\title{
Gestão do conhecimento em organizações públicas complexas: um estudo de caso na UFRPE
}

\author{
Ariella Rayder Gomes de Souza Cahú- ariellarayder@yahoo.com.br ${ }^{1}$ \\ Catarina Rosa e Silva de Albuquerque- catarinarosaesilva@hotmail.com² \\ Ionete Cavalcanti de Moraes- ionetemoraes@gmail.com ${ }^{3}$ \\ Jorge da Silva Correia-Neto- jorgecorreianeto@gmail.com ${ }^{4}$
}

\begin{abstract}
Resumo - O conhecimento é a grande finalidade de uma universidade e a gestão de conhecimento (GC) situa-se na criação, identificação, integração, recuperação, compartilhamento e utilização do conhecimento nas organizações. Dada a complexidade das universidades brasileiras, buscou-se investigar o nível de maturidade em GC da UFRPE, por perfil profissional. O estudo é caracterizado como descritivo e quantitativo. Utilizou-se o modelo de Batista para instituições públicas, com adaptações para a realidade institucional. A análise de 245 questionários respondidos classificou a universidade no Nível Iniciação em GC. As percepções são diferentes conforme o perfil analisado, mas todas apontam no sentido de que é preciso avançar muito na GC. Também são apresentadas as limitações do estudo e indicações de estudos futuros.
\end{abstract}

Palavras-chave: Gestão do Conhecimento. Universidades. Nível de Maturidade.

\section{Knowledge management in complex public organizations: a case study at UFRPE}

\begin{abstract}
Knowledge is the great purpose of a university and knowledge management (KM) encompasses the creation, identification, integration, retrieval, sharing and use of knowledge within an organization. Given the complexity of the Brazilian universities, we sought to investigate the level of maturity in KM at UFRPE, by professional profile. The study is characterized as descriptive and quantitative. Batista's model for public institutions was used, with adaptations to the institutional reality. The analysis of 245 questionnaires answered classified the university in the KM Initiation Level. The perceptions are different according to the profile analyzed, but all point in the sense that it is necessary to advance a lot in KM. Study limitations and indications for future studies are also presented.
\end{abstract}

Keywords: Knowledge Management. Universities. Maturity Level. 


\section{INTRODUÇÃO}

Como já apontavam Sharimllah Devi, Chong e Lin (2007), para as universidades tornarem seu ambiente educativo mais dinâmico e com mais atividades de intercâmbio de conhecimentos é preciso gerir o conhecimento ali produzido. Ademais, a gestão do conhecimento (GC) é uma importante ferramenta, já que a atividade fim ou missão da universidade é a construção do conhecimento científico e social, formação intelectual e profissional do indivíduo.

No contexto das universidades brasileiras, além dos estudantes de graduação e de pós-graduação existem também os técnicos que exercem atividades administrativas, científicas e de apoio educacional, além dos pesquisadores / docentes, especializados por área de competência e linhas de pesquisa. Além de toda a atmosfera física da universidade, que permite encontros e conexões entre esses indivíduos nas salas de aula, nos cafés, auditórios, e grupos de pesquisa, ainda existem os grupos informais que se utilizam de várias ferramentas de tecnologia da informação e comunicação (TIC) para o compartilhamento de informações fora da universidade (EID; AL-JABRI, 20I6).

É neste sentido que a GC se apresenta como suporte ao processo estratégico de planejamento e difusão de informações, especialmente desse tipo de organização, pois como aponta a teoria da complexidade, permite que as partes sejam entendidas dentro de um contexto geral (SERVA; DIAS; ALPERSTEDT, 20Io), dado que as universidades estão ligadas a outros elos e sistemas que interagem e se influenciam mutuamente.

A partir deste contexto e de um estudo de caso realizado na Universidade Federal Rural de Pernambuco (UFRPE), a investigação buscou responder a seguinte pergunta de pesquisa: como os docentes e técnicos entendem e avaliam as ações de GC na UFRPE? Para responder a essa pergunta traçou-se como objetivo investigar o nível de nível de maturidade da GC na UFRPE. Mais especificamente buscou-se i) avaliar a percepção de docentes e técnicos administrativos acerca dos processos de GC e; ii) a influência desses profissionais estarem exercendo, ou terem exercido, funções de gestão em sua percepção acerca dos processos de GC.

\section{FUNDAMENTAÇÃO TEÓRICA}

Essa seção sintetiza o suporte teórico da pesquisa desenvolvida, mais especificamente a teoria da complexidade e a gestão do conhecimento.

\subsection{Teoria da Complexidade}

$\mathrm{Na}$ teoria da complexidade a educação pode ser vista como um sistema com conexões, holístico (considera a totalidade) e não linear (MANSON, 2008). Por estar atrelado a diversos sistemas, a universidade é uma esfera que entrelaça diversos profissionais, até mesmo de nações diferentes, que colaboram em pesquisas interessantes do ponto de vista da produção e da qualidade científica. Mas, para a excelência ocorrer é necessário que a universidade seja um centro produtor de conhecimento e de formação de capital humano (TODERICIU; ŞERBAN, 2OI5).

Dessa forma, as instituições de ensino superior podem ser consideradas sistemas complexos de rede de aprendizado, repleta de stakeholders, com forte especialização dos membros e que busca uma eficiência central e relevância no desenvolvimento econômico-social, com 
interações não-lineares de seus membros (TEIXEIRA; GUERRA, 2002; MEYER, 20I4).

Ademais, as organizações complexas são configuradas em determinados padrões e dimensões do espaço/tempo e fazem intercâmbios com a sociedade; possuem forças sociais motoras que fazem codificações e centralização (MORIN; LE MOIGNE, 2000; NOGUEIRA, 2003; TRAGTENBERG, 20I8). Consoante, trata-se de um sistema complexo e, mesmo que essa pesquisa estude apenas uma única universidade pública brasileira, pode ser que haja um padrão mensurável na aparente aleatoriedade dos resultados comparativos em posteriores pesquisas de outras universidades públicas de tamanhos diferentes e de outras regiões do país.

Ainda neste contexto, Handzic (2004) usa uma metáfora para descrever a organização do conhecimento que inclui sistema de produção ágil, organismo vivo, sistema adaptativo complexo, sistema auto organizado e organização virtual. Entende-se que a produção ágil é necessária para o funcionamento da organização, o organismo vivo é a rede de relações internas e externas que mantém a organização viva; o sistema adaptativo complexo responde com criatividade e inovação às mudanças ambientais e o sistema é auto organizado porque os grupos e as lideranças se motivam pelo compartilhamento de conhecimento mútuo e a organização também pode ser virtual utilizar as ferramentas de TIC para compartilhamento de conhecimento.

\subsection{Gestão do Conhecimento}

As subseções seguintes discutem a sociedade do conhecimento, a gestão do conhecimento organizacional e os modelos de avaliação da GC.

\subsubsection{A sociedade do conhecimento}

O Quadro I sumariza os paradigmas industriais e da sociedade do conhecimento, na visão de Sveiby (1998), demonstrando como uma sociedade inteira está sendo direcionada para o conhecimento e como essa mudança afetará as relações sociais, econômicas e de trabalho nas organizações.

Quadro I. Paradigmas industriais e do conhecimento.

\begin{tabular}{|l|l|l|}
\hline Item & Paradigma industrial & Paradigma do conhecimento \\
\hline Pessoas & Geradores de custos & Geradores de receita \\
\hline Base de poder dos gerentes & $\begin{array}{l}\text { Nível relativo na hierarquia } \\
\text { organizacional }\end{array}$ & Nível relativo de conhecimento \\
\hline Luta de poder & $\begin{array}{l}\text { Trabalhadores físicos versus } \\
\text { capitalistas }\end{array}$ & $\begin{array}{l}\text { Trabalhadores do conhecimento versus } \\
\text { gerentes }\end{array}$ \\
\hline Principal tarefa da gerência & Supervisão de subordinados & Apoio aos colegas \\
\hline Informação & Instrumento de controle físicos & Ferramenta para o recurso da comunicação \\
\hline Produção & $\begin{array}{l}\text { Trabalhadores conhecimento } \\
\text { processando recursos físicos } \\
\text { para criar recursos tangíveis }\end{array}$ & $\begin{array}{l}\text { convertendo conhecimento em estrutura } \\
\text { intangível }\end{array}$ \\
\hline Fluxo de informações & Via hierarquia organizacional & Via redes colegiadas \\
\hline Forma básica de receita & Tangível (dinheiro) & $\begin{array}{l}\text { Intangível (aprendizado, novas ideias, } \\
\text { novos clientes, P\&D) }\end{array}$ \\
\hline $\begin{array}{l}\text { Estrangulamentos } \\
\text { produção }\end{array}$ & $\begin{array}{l}\text { Capital financeiro } \\
\text { habilidades humanas }\end{array}$ & Tempo e conhecimento \\
\hline
\end{tabular}




\begin{tabular}{|l|l|l|}
\hline Manifestação da produção) & Produtos tangíveis (hardware) & $\begin{array}{l}\text { Estruturas intangíveis (conceitos e } \\
\text { softwares) }\end{array}$ \\
\hline Fluxo de produção & $\begin{array}{l}\text { Regido pela máquina, } \\
\text { sequencial }\end{array}$ & Regido por ideias, caótico. \\
\hline Efeito de porte & $\begin{array}{l}\text { Economia de escala no } \\
\text { processo de produção }\end{array}$ & Economia de escopo nas redes \\
\hline $\begin{array}{l}\text { Relacionamento com o } \\
\text { cliente }\end{array}$ & Unilateral pelos mercados & Interativo pelas redes pessoais \\
\hline Conhecimento & $\begin{array}{l}\text { Uma ferramenta ou um recurso } \\
\text { entre outros }\end{array}$ & O foco empresarial \\
\hline Finalidade de aprendizado & $\begin{array}{l}\text { Aplicação de novas } \\
\text { ferramentas }\end{array}$ & Criação de novos ativos \\
\hline $\begin{array}{l}\text { Valores do mercado } \\
\text { acionário }\end{array}$ & Regidos pelos ativos tangíveis & Regidos pelos ativos intangíveis \\
\hline Economia & De redução de lucros & De aumento e redução de lucros \\
\hline
\end{tabular}

Fonte: baseado em Sveiby (I998).

Cabe ainda salientar que, como indicam Turban, Efrain e Potter (2005), dados são coleções de fatos, informações são dados organizados e precisos, e o conhecimento é a informação contextual, relevante e acionável. "Informações descrevem que os dados possuem contexto, relevância e propósito" (BECERRA-FERNANDEZ; LEIDNER, 2008, p. 4-5) e o conhecimento nem é dado nem informação; é uma ordem mais elevada, como a sabedoria, e próxima da ação, com os seres humanos transformando a informação em conhecimento por meio da comparação, avaliação das consequências, conexões e conversações (DAVENPORT; PRUSAK, 2003; SILVA, 2004).

Os ativos intangíveis que agregam valor à maioria dos produtos e serviços são baseados em conhecimento, sendo possível citar o know-how técnico, o entendimento do cliente, a criatividade pessoal e a inovação (SANTIAGO; SÁTIRO, 2004), mas como os economistas apontam, a produção de um bem da informação envolve altos custos fixos e baixos custos marginais na reprodução (SHAPIRO; VARIAN, 2003).

Handzic (2004, p. 4) observa ainda que "esse mundo emergente é referente como uma terceira onda, era da informação, conhecimento base ou economia do conhecimento ou sociedade". Assim, viver na Sociedade do Conhecimento é lidar com o trabalhador do conhecimento cujo labor é intelectual, com novas carreiras e qualificações, identidades sociais e relacionamentos, onde o conhecimento é o recurso-chave dos trabalhadores nessas novas exigências atuais (DRUCKER, 2002).

Por isso muitas organizações criaram o cargo de diretor de conhecimento (Chief Knowdlege Officer - CKO) no nível executivo, que maximiza os ativos de conhecimento da firma, projeta e implementa estratégias da gestão do conhecimento e troca esse ativo internamente e externamente (TURBAN; RAINER; POTTER, 2005). A criação de um cargo específico apenas para gestão do conhecimento é uma forma de entender a importância da GC para a organização, já que esse ativo demanda suporte, ações, tempo e diretrizes que aperfeiçoem os processos de forma profissional e especializada. Dentro das universidades, a gestão do conhecimento toma contorno relevante porque é a instituição que lida com o conhecimento em várias áreas do saber. 


\subsubsection{A gestão do conhecimento organizacional}

A GC em organizações pode adotar ênfase em processos, procedimentos, práticas ou lições aprendidas, incluindo não só uma percepção, mas uma estratégia de comportamento organizacional que precisa ser aprendido. Por isso, Becerra-Fernandez e Leidner (2008, p. 4) salientam que "aprender como gerenciar o conhecimento organizacional [...] pode alavancar as maiores competências do negócio, acelerar inovação".

Carvalho (20I2) afirma ainda que comunidades de prática, inteligência competitiva e memória organizacional são conceitos importantes da gestão do conhecimento, mas para haver uma conversão contínua de informação em conhecimento é preciso existir a comparação com situações similares, pois as consequências são os efeitos das decisões e ações, as conexões são relacionadas com o conhecimento acumulado e as conversações são atreladas ao pensamento das pessoas sobre a informação.

De acordo com Boff (200I), gestão de conhecimento é um conjunto de estratégias para criar, adquirir, compartilhar e utilizar ativos de conhecimento, estabelecer fluxos que garantam a informação necessária no tempo e formato adequados, a fim de auxiliar na geração de ideias, solução de problemas e tomada de decisão. Chouikha (2006, p. 42-5I) destaca "cinco pontos da literatura sobre gestão de conhecimento que incluem: estratégia, estrutura, tecnologia, pessoas e sistemas de incentivo". Na literatura recente, também menciona que para melhorar os processos internos de gerenciamento desse ativo, a gestão do conhecimento visa trazer esse conhecimento tácito para a socialização dentro das organizações, que atuam como uma maneira de garantir melhorias internas e fortalecimento dos seus diferenciais em relação aos concorrentes. Dessa forma, o conhecimento pode ser: socializado, externalizado ou combinado englobando toda política organizacional.

Segundo Nonaka e Takeuchi (I997), não existe uma forma única de se conceituar conhecimento e de se gerir esse ativo. Para eles, tácito é o conhecimento individual, frequentemente não gerenciável, muito importante, mas difícil de ser articulado pela linguagem formal por que envolve fatores intangíveis como crenças pessoais, perspectivas e sistemas de valores. Assim, a criação do conhecimento envolve o indivíduo, o grupo e a organização.

Como apontam Nonaka e Takeuchi (1997) na Figura I, a socialização se inicia por meio da interação entre diversos atores, que pode levar à externalização, desencadeada pelo diálogo ou reflexão coletiva. Em seguida, a combinação é desencadeada pela rede do conhecimento recente e daquele já existente, cristalizando um novo produto, serviço. Por fim, a internalização acontece com o aprender fazendo.

Por meio da GC as organizações não somente processam o conhecimento, mas também o criam (NONAKA; TAKEUCHI, I997), e isso deve ser institucionalizado por múltiplas ações que visam incorporar conceitos, princípios, práticas e ferramentas gerenciais nos seus modelos de gestão (SANTOS; LEITE; FERRARESI, 2007). 
Figura I. Espiral do Conhecimento

Diálogo

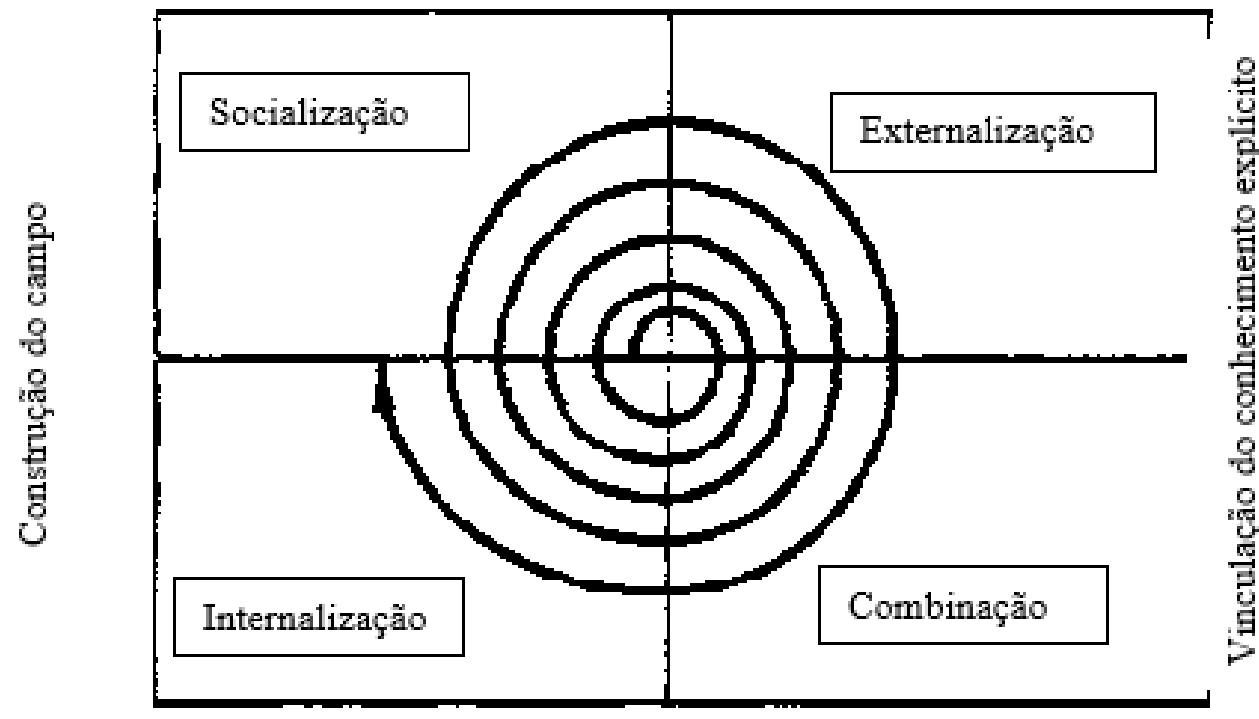

$\frac{2}{2}$

Aprender fazendo

Fonte: Nonaka e Takeuchi (I997, p. 69-70)

Dessa maneira, as organizações podem investir nas estruturas, mas o conhecimento é um elo importante que, quando atua em cadeia, afeta produtos ou serviços. Nonaka e Takeuchi (1997) estabelecem ainda que a constituição da criação do conhecimento envolve a transformação do tácito para o explícito (externalização), do explícito para o explícito (combinação), do explícito para o tácito (internalização) e do tácito para o tácito (sociabilização).

Por outro lado, parte dos problemas/erros sobre a disponibilidade de conhecimentos engloba transferência do conhecimento, falta de conhecimento, conhecimento crítico nas mãos de poucos, impossibilidade de medição do uso do conhecimento, perda de conhecimentos relevantes nos momentos adequados e falta de processos de compartilhamento (SANTIAGO, 2004). Para aplicação da mensuração prática acerca da situação dos problemas apresentados por Santiago, há diversos tipos de sistemas de gestão de conhecimento (Knowledge Management Systems - KMS) os quais agilizam a gestão de conhecimento nas empresas. Essas ferramentas funcionam como um ciclo com as seguintes etapas: criação, captura, refino, armazenamento, gerenciamento e disseminação (TURBAN; RAINER; POTTER, 2005).

Contudo, também pode haver tensões na transferência e distribuição do tácito conhecimento por causa do comportamento das pessoas, caso haja obstáculos tais como baixa motivação dos atores que possuem esse conhecimento, comitês fechados de diretores, falta de comprometimento com o passado da companhia, cultura vertical e compartimentalização na circulação de informação (CHOUIKHA, 20I6).

Por fim, cabe destacar que algumas organizações públicas brasileiras já experienciam a GC. É o caso do Serviço Federal de Processamento de Dados (SERPRO), que é a maior empresa pública de TIC do mundo e há 50 anos moderniza o Estado brasileiro com soluções estratégicas para o país, inclusive com o Processo Corporativo do Conhecimento Organizacional (SERPRO, 20I8; SANTOS et al., 200I). A gestão de conhecimento no SERPRO possui os seguintes componentes: gestão dos conhecimentos organizacionais, gestão de competências, gestão de talentos, 
busca de melhores práticas, desenvolvimento de pessoas, aprendizagem organizacional e comitê permanente de representantes (SANTOS et al., 200I).

\subsection{Modelos de avaliação relacionados à gestão do conhecimento}

Quanto à mensuração das ações relacionadas com GC existem duas grandes linhas: indicadores e modelos de avaliação da GC, e modelos baseados no nível de maturidade (GONÇALO; JUNGES; BORGES, 20I0). Batista (20I2) e a Productivity Organization (APO) optaram pelos modelos de maturidade.

A APO, organização de origem oriental, estabeleceu cinco passos ou degraus do processo da GC: identificando, criando, armazenando, compartilhando e aplicando conhecimento (APO, 2009). Como sintetiza o Quadro 2, mesmo que a organização não tenha ferramentas sofisticadas no nível tecnológico (softwares), há também alternativas que podem ser implementadas, como por exemplo, espaços de convivência.

Quadro 2. Síntese das ferramentas de avaliação da GC

\begin{tabular}{|l|l|}
\hline Sobre oconhecimento & Ferramenta de avaliação \\
\hline Identificando & $\begin{array}{l}\text { Cafés de conhecimento; comunidades de prática; ferramentas de pesquisa } \\
\text { avançada; clusters de conhecimento; localizador de especialistas; espaços de } \\
\text { trabalho virtuais colaborativos; mapeamento do conhecimento; modelo de } \\
\text { maturidade da GC. }\end{array}$ \\
\hline Criando & $\begin{array}{l}\text { Brainstorming; aprendizagem e captura de idéias; revisões de aprendizagem; } \\
\text { revisões de ação; espaços de trabalho físicos colaborativos; cafés de conhecimento; } \\
\text { comunidades de prática; bases de conhecimento (wikis e blogs); voz e voip; } \\
\text { pesquisa avançada; mentor; portal de conhecimento; compartilhamento de vídeo } \\
\text { estudo de caso de visões étnicas. }\end{array}$ \\
\hline $\begin{array}{l}\text { Armazenando } \\
\text { Conhecimento }\end{array}$ & $\begin{array}{l}\text { Revisões de aprendizagem após revisões de ação; cafés de conhecimento; } \\
\text { comunidades de prática; taxonomia; bibliotecas de documentos; conhecimento } \\
\text { clusters; expert locator; espaços de trabalho virtuais colaborativos; portal do } \\
\text { conhecimento; compartilhamento de vídeo estudo de caso de visões étnicas }\end{array}$ \\
\hline $\begin{array}{l}\text { Compartilhando } \\
\text { Conhecimento }\end{array}$ & $\begin{array}{l}\text { Revisões de aprendizagem; resenhas de ação; contação de histórias; comunidades } \\
\text { de prática; áreas de trabalho físicas colaborativas; cafés de conhecimento; } \\
\text { comunidades de prática; taxonomia; bibliotecas de documentos; bases de } \\
\text { conhecimento (wikis e blogs); serviços de redes sociais, voz e voip; clusters } \\
\text { de conhecimento; localizador de especialistas; espaços de trabalho virtuais } \\
\text { colaborativos; portal de conhecimento. compartilhamento de vídeo; estudo de } \\
\text { caso de visões étnicas mentor. }\end{array}$ \\
\hline $\begin{array}{l}\text { Aplicando } \\
\text { Conhecimento }\end{array}$ & $\begin{array}{l}\text { Espaços de trabalho físicos colaborativos; cafés do conhecimento; comunidades } \\
\text { de prática; taxonomia; bibliotecas de documentos; bases de conhecimento } \\
\text { (wikis e blogs); pesquisa avançada; clusters de conhecimento; localizador de } \\
\text { especialistas, espaços de trabalho virtuais colaborativos; plano de competência } \\
\text { do trabalhador do conhecimento; mentor; portal de conhecimento estudo de caso } \\
\text { de visões étnicas. }\end{array}$ \\
\hline
\end{tabular}

Fonte: Adaptado de APO (20I0).

As ferramentas que a APO apresenta podem ser implantadas a depender da cultura da organização e também podem ser flexibilizadas de acordo o tamanho, poder econômico e a cultura da instituição. Há também a American Productivity and Quality Center (APQC), cujo modelo também foi utilizado por Batista (20I2) na formulação do modelo brasileiro, apresentado na Figura 2. 
Figura 2. Modelo de Gestão do Conhecimento para a administração pública.

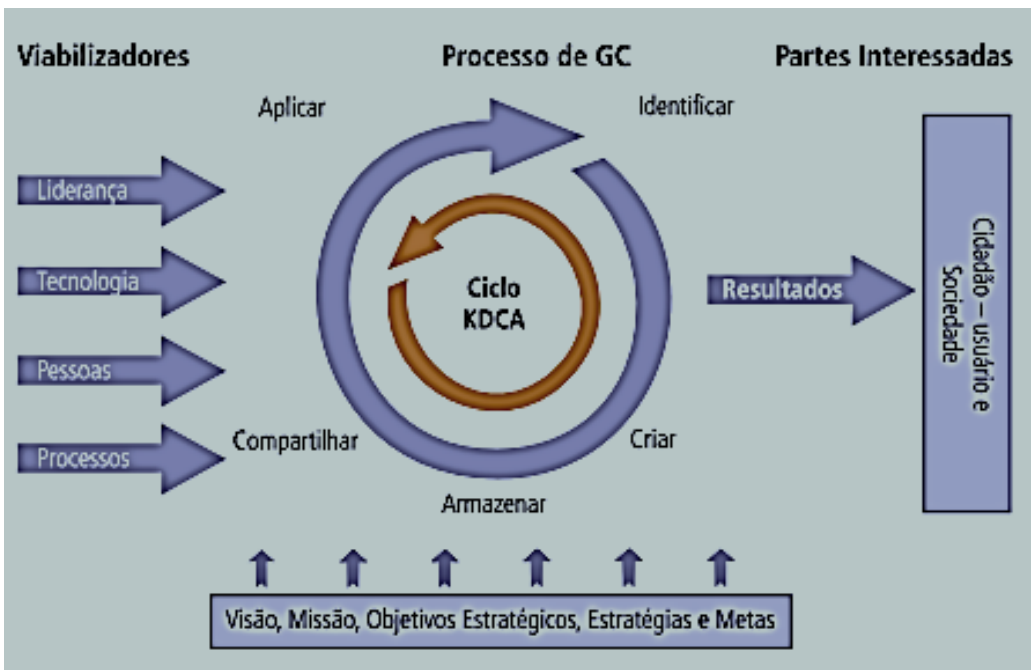

Fonte: Batista (20I2).

O modelo de Batista (20I2) é um instrumento analítico e generalista que leva em consideração a realidade das organizações públicas brasileiras, e por esse motivo foi escolhido como mais adequado para esta pesquisa na UFRPE. O modelo elenca os seguintes fatores críticos de sucesso ou viabilizadores da GC:

- Liderança: alocação de recursos humanos e financeiros para viabilizar as iniciativas e dirigir o esforço de implementação da GC. É fator importante para arranjos da GC, incluindo suas equipes e o cuidado com direitos autorais, patentes e segurança do conhecimento;

- Tecnologia: viabiliza e acelera os processos de GC. Permite a existência de mecanismos de busca, repositórios de conhecimentos; sistemas de workflow (controle da qualidade da informação via automação do fluxo de documentos) e a gestão de conteúdo, além da gestão eletrônica de documentos (GED);

- Pessoas: desempenham um papel importante nos processos principais de GC. Fóruns (presenciais e virtuais) / listas de discussão, comunidades de prática (grupos informais e interdisciplinares de pessoas unidas em torno de um interesse comum), educação corporativa e universidade corporativa;

- Processos: conjunto de atividades que transformam insumos (entradas) em produtos e serviços (saídas) na organização, por meio de pessoas e recursos adequados às melhores práticas, gestão do capital intelectual ou gestão dos ativos intangíveis;

- Processos em GC:

$\checkmark$ Identificar lacunas: por meio de um instrumento, adaptado à administração pública, avaliar a situação atual;

$\checkmark$ Criar: a organização pública elimina as lacunas do conhecimento por meio da conversão do conhecimento e a criação de novo conhecimento por meio de brainstormings, cafés do conhecimento, etc.;

$\checkmark$ Armazenar: o armazenamento permite a preservação do conhecimento organizacional; 
Compartilhar: o compartilhamento do conhecimento promove a aprendizagem contínua e a inovação e, consequentemente, permite atingir os objetivos organizacionais;

$\checkmark$ Aplicar: a aplicação da GC deve trazer a melhoria de produtos e serviços na organização pública. A aplicação também pode ser em cafés do conhecimento, comunidades de prática, etc.;

$\checkmark$ Resultados: podem ser resultados imediatos e os resultados finais. Novas tecnologias, projetos, políticas públicas, práticas inovadoras.

De todos os fatores críticos elencados por Batista (20I2), destaca-se a liderança, que tende a ser rotativa nas empresas e até mesmo nas organizações públicas. A rotatividade pode colaborar para um movimento destrutivo acerca da $\mathrm{GC}$, caso a próxima equipe desfaça o trabalho anterior ou até mesmo interrompa processos positivos implantados. Dessa forma, é importante a continuidade das políticas que envolvam a GC como uma bússola da organização.

É notório que o fator pessoas salienta a relevância da sociabilidade dos indivíduos das organizações como ponto forte quando estão interligadas umas às outras numa rede de colaboradores ativos e participativos para criação e compartilhamento de conhecimento. Contribui para esse reforço até mesmo o quesito processos, que também reconhece o papel dos indivíduos da organização, pois conta com a identificação e localização não só dos procedimentos já estabelecidos, mas também das pessoas e equipes que já possuem know how nos assuntos específicos. Acrescenta-se que o modelo proposto também conta com a execução da GC por meio do ciclo KDCA, que é baseado no ciclo PDCA (Plan, Do, Check, Action). No KDCA o planejamento é substituído por $\mathrm{K}(\mathrm{K}=$ knowledge $=$ conhecimento $)$.

Batista (20I2) também estabelece quatro etapas para implementação de um plano de GC em uma instituição: diagnóstico, planejamento, desenvolvimento e implementação. Os critérios que integram o instrumento para avaliação de Batista (20I2) estão no esquema da figura 3.

Figura 3. Critérios de avaliação da GC. Fonte: Batista (20I2).

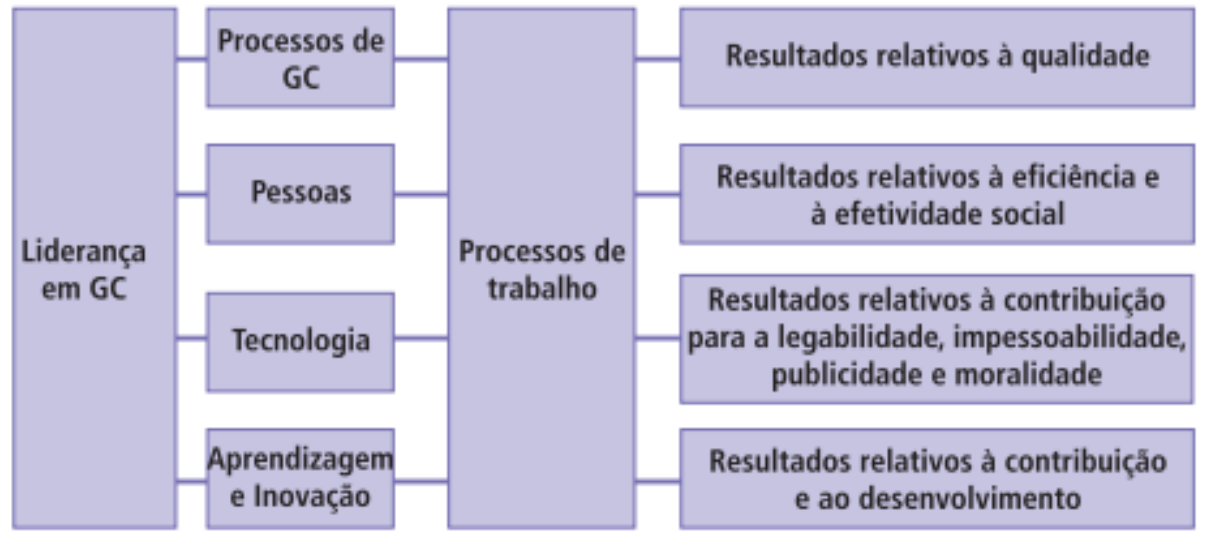

Práticas para viabilizar GC

Resultados de GC

Fonte: Batista (20I2). 
Em resumo, o critério de liderança em GC examina se a visão e a estratégia de GC estão alinhadas com os direcionadores estratégicos da organização e se são compartilhados. O processo avalia se a organização define suas competências essenciais e as alinha à sua missão e objetivos; pessoas indicam se os programas de educação e capacitação ampliam o conhecimento, as habilidades e as capacidades do servidor público e o apoiam no alcance dos objetivos da organização; tecnologia verifica se há infraestrutura de TIC para apoio à GC; aprendizagem e inovação avaliam se a organização articula e reforça como valores a aprendizagem e inovação; resultados da GC analisa se a organização tem histórico de implementação da GC.

Enfim, pontuação total para conseguir o Nível de Maturidade em Gestão do Conhecimento da UFRPE levou em consideração os dados obtidos em conformidade com a seguinte escala do modelo Batista (20I2):

- Reação (42-83): revela que a instituição não sabe o que é GC e desconhece a sua importância para aumentar a eficiência e melhor efetividade social;

- Iniciação (84-I25): é quando a organização começa a reconhecer a necessidade de gerenciar o conhecimento;

- Introdução (I26-I46): quando há práticas de GC em algumas áreas;

- Refinamento (I47-I88): quando a implementação da GC é avaliada e melhorada continuamente.

\section{PROCEDIMENTOS METODOLÓGICOS}

O presente estudo é caracterizado como descritivo e de abordagem quantitativa. Foi realizado um survey na UFRPE, no campus sede em Recife, a partir do questionário desenvolvido por Batista (20I2), respondido de forma individual, presencialmente ou por e-mail. Como a realidade da instituição conta com pluralidade de formações acadêmicas, a redação do questionário foi adaptada para facilitar a comunicação e foram retiradas palavras técnicas da área de administração.

O público da pesquisa foi composto por servidores do perfil docente e do técnico. A pesquisa avaliou também os dados segmentados pelos seguintes grupos: docentes com e sem cargos de gestão, e técnicos com e sem cargos de gestão.

A quantidade amostral mínima de respondentes foi calculada com base na população total de servidores da UFRPE, que é de aproximadamente 2200 , com grau de erro amostral de $5 \%$ e nível de confiança de $90 \%$. A pesquisa contou com 245 respondentes válidos, o que superou o índice mínimo do tamanho da amostra. A coleta foi feita em um smartphone ou enviada em links por e-mail e/ou WhatsApp. O questionário foi disponibilizado na Google Forms.

Os dados foram analisados com o programa Excel Id 00202-52634-55495-AA95I, versão I808, Office 365 (64 bits) original e licenciado. Dentre os técnicos somaram-se 204 pessoas, dentre as quais 82 com cargos de gestão e I 22 sem. Já dentre os docentes houve 4I respondentes, sendo 28 com cargos de gestão e I3 sem. 


\section{RESULTADOS}

Entre os respondentes I27 (52\%) eram do gênero feminino e II8 (48\%) do masculino. Foram IIo (45\%) respondentes com cargos de confiança, função de direção, coordenação ou correspondentes, contra $135(55 \%)$ que nunca haviam estado nessas funções. Dentre os respondentes $224(92 \%)$ tinham nível superior, enquanto apenas com ensino médio foram $20(8 \%)$ e I com ensino fundamental. Nota-se a expressiva quantidade de especialistas (96-39\%) e de servidores com altos estudos (mestrado e doutorado) (92-37,5\%). Desse fato, deduz-se que os técnicos estão se inserindo nos altos estudos tendo em vista que são a maioria da amostragem.

Observou-se que os técnicos com cargo de gestão apresentaram a melhor avaliação em Tecnologia $(3,16)$ e a menor em Processo do Conhecimento $(2,25)$. Já os técnicos do perfil sem cargo de gestão avaliaram o critério Processo do Conhecimento com a menor média de todos os critérios $(2,43)$ e a maior média foi para o critério Tecnologia $(3,25)$. Como mostra a Figura 4, ambos os perfis de técnicos convergem na mesma visão da instituição e a diferença é que os técnicos com cargo de gestão foram mais críticos e deram notas menores aos critérios.

Figura 4. Média do Nível de Maturidade em GC da UFRPE na visão dos técnicos com e sem cargos de gestão.

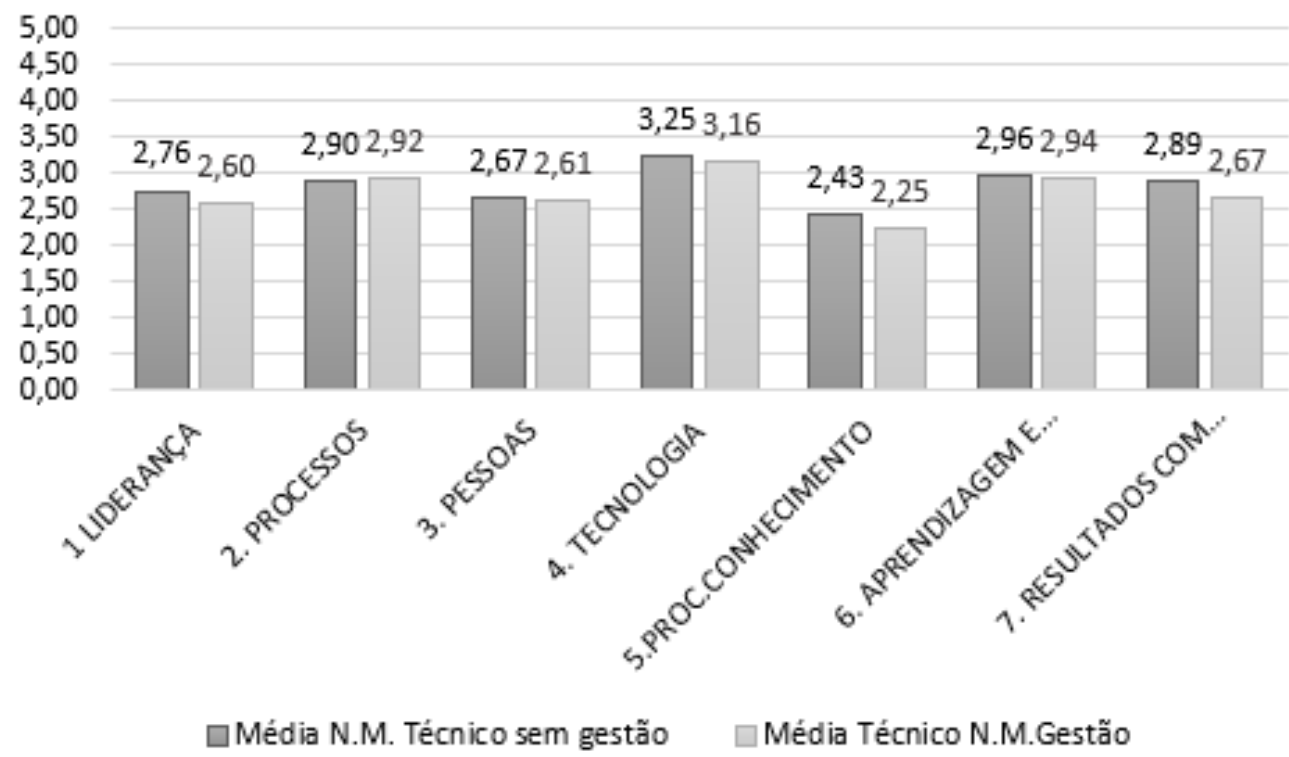

A Figura 5 apresenta os resultados inerentes ao grupo de docentes com e sem cargos de gestão. Salienta-se que os docentes com cargo de gestão apresentaram a maior média do nível de maturidade em GC no item Tecnologia $(3,24)$ e a menor avaliação foi no critério Processo do Conhecimento $(2,49)$. Interessante notar que os técnicos com gestão avaliaram o critério liderança com pontuação menor do que os docentes com cargo de gestão $(2,60 / 2,74)$. Entretanto, os técnicos sem cargo de gestão avaliaram esse item com pontuação maior do que a dos docentes com cargo de gestão $(2,76)$.

Em comparação, os docentes sem cargo de gestão deram pontuações maiores do que os docentes com cargo de gestão em todos os critérios da pesquisa. Destaca-se a pontuação do critério Tecnologia $(3,62)$ com a melhor pontuação de todos os perfis e a menor pontuação foi para o critério Processos, que teve média 2,95. 
Por outro lado, o grupo dos docentes sem cargo de gestão divergiu na pontuação do critério Processos de Conhecimento, que foi o critério com menor nota nos perfis técnicos sem cargo de gestão, técnicos com cargo de gestão e docentes com cargo de gestão. Dessa maneira a menor pontuação desse perfil foi para o critério Processos.

O comparativo das médias do Nível de Maturidade em GC para docentes também demonstra que a visão da maturidade em GC da UFRPE é dissonante entre os docentes dos dois perfis e apenas as pontuações dos critérios Aprendizagem (6) e Processos (2) possuem médias mais aproximadas.

Figura 5. Médias do Nível de Maturidade em GC da UFRPE sob ótica dos docentes com e sem cargos de gestão.

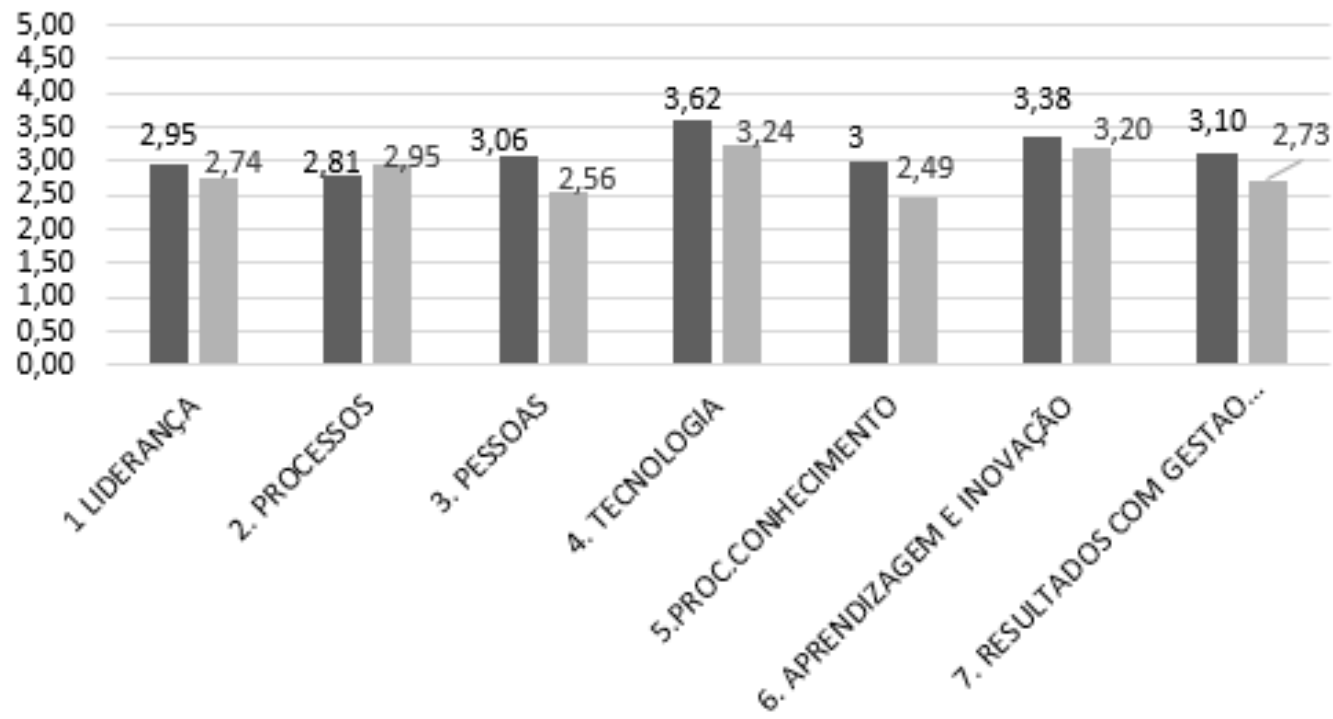

匹 Média Docente N.M. UFRPE (Sem Gestão) — Média N.M. UFRPE Docente Gestão

Já a Figura 6 mostra que a Média do Nível de Maturidade é maior no critério Pessoas quando pontuamos juntos os dois perfis docentes (com e sem cargos de gestão) como apenas o grupo docente. Há também uma boa pontuação no critério Aprendizagem e Inovação. Porém, o critério Processo do Conhecimento está com a média baixa em relação aos outros itens.

Figura 6. Nível de Maturidade GC da UFRPE sob ótica dos docentes.

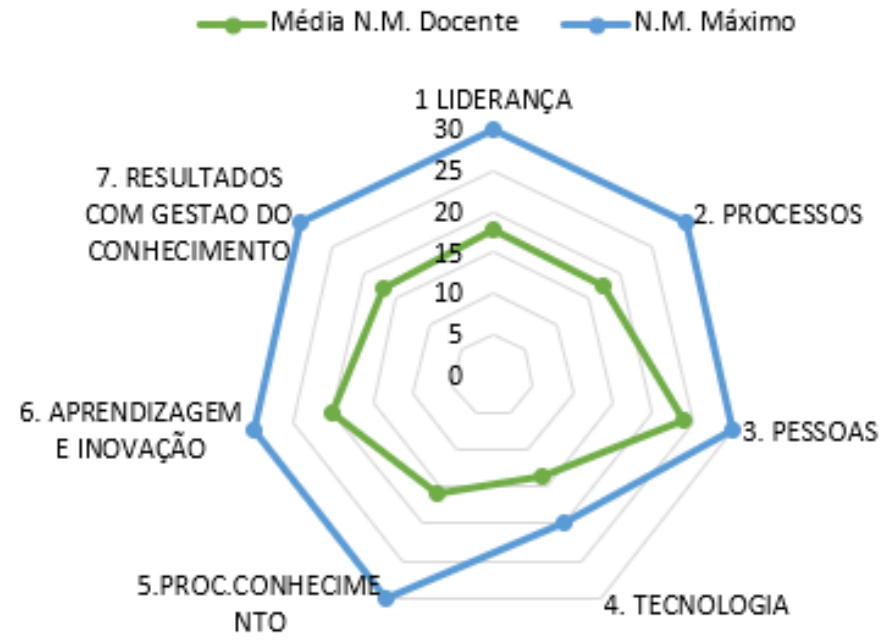


Por outro lado, o gráfico radar dos técnicos (perfis com e sem cargos de gestão) possui nítida diferença em relação ao critério Pessoas dos docentes. Também é notório que o critério Tecnologia teve uma convergência de opiniões dos dois grandes grupos de servidores pesquisados. Nesse sentido, a universidade conta com o sistema Sig@processos que abarca os processos administrativos e sua tramitação, além do Siga@UFRPE que conta com dados dos discentes e do perfil do administrador ou docente. Há também tecnologia por todo o campus como $\mathrm{Wi}-\mathrm{Fi}$ para servidores e estudantes que sozinhos conseguem configurar a senha de acesso por meio da plataforma Sig@.

Na Figura 7 ainda podemos perceber que, numa mesma universidade, há visões diferentes de como funciona a instituição e deduz-se que os planos de carreira divergem assim como os ambientes de trabalho. Dessa forma, há possibilidade de esses serem fatores que alterem a percepção dos indivíduos diante das condições de trabalho e da Gestão do Conhecimento na instituição.

Figura 7. Nível de Maturidade GC da UFRPE sob ótica dos técnicos.
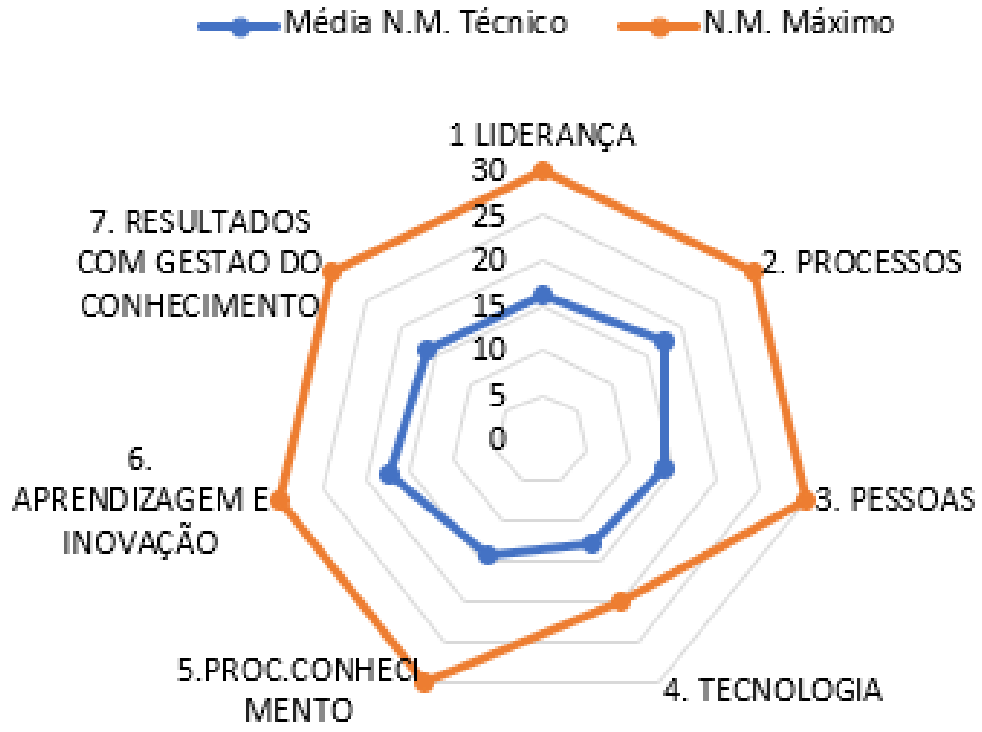

Por fim, observa-se na Figura 8 a sobreposição dos radares das médias do Nível de Maturidade em relação ao total do Nível de Maturidade, e a aproximação de alguns pontos para cada grupo. 
Figura 8. Nível de Maturidade GC da UFRPE com sobreposição das médias parciais de técnicos e de docentes, e da média global.

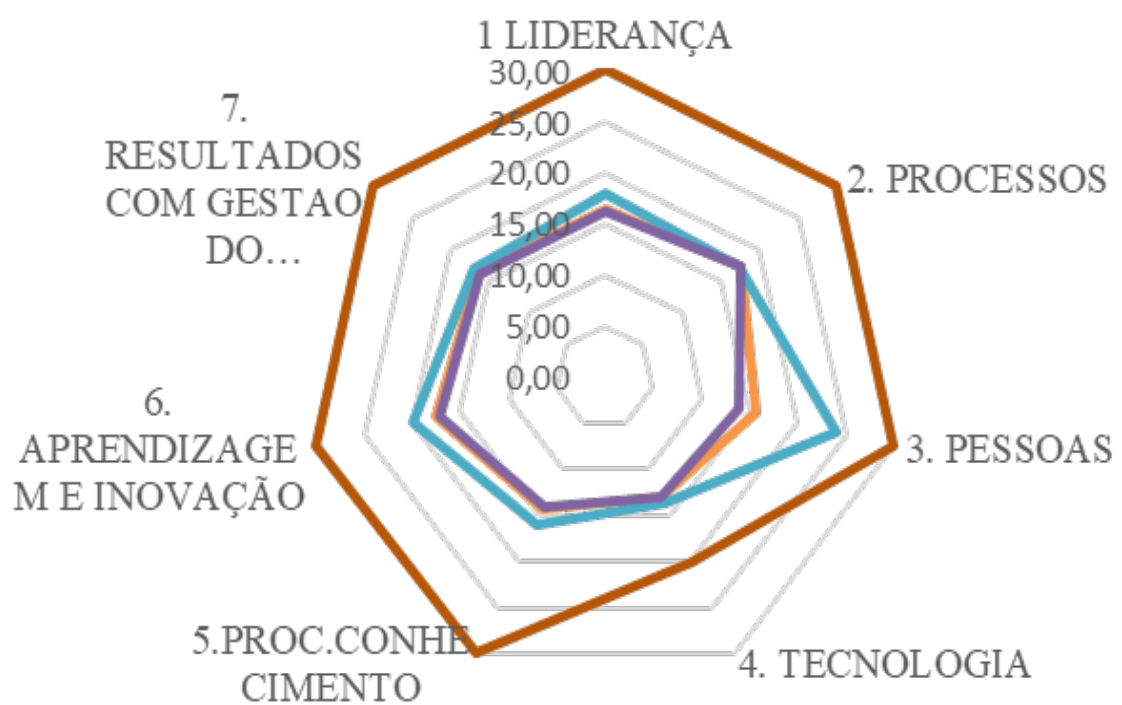

Desse modo, houve também a somatória de todas as médias por nível de maturidade por critério. De acordo com a escala prevista por Batista (20I2), a pontuação IIo,88 determina que a UFRPE está no nível Iniciação em GC. Deduz-se que a instituição está no segundo patamar da escala que vai até 5 degraus, sendo preciso consubstanciar as ferramentas de GC para melhorar as médias dos critérios.

\section{CONSIDERAÇÕES FINAIS}

A presente pesquisa teve como objetivo investigar a maturidade em GC de organizações complexas, tomando o caso da UFRPE. Para cumprir essa meta, fez-se a aplicação de questionários utilizando o modelo de Batista (20I2), adaptado. Utilizando uma metodologia descritiva, quantitativa, investigou-se a percepção de dois grandes grupos de servidores, os docentes e técnicos administrativos, acerca da maturidade em GC da UFRPE.

Os resultados podem contribuir para a UFRPE no que tange à possibilidade do uso dos dados da GC para melhoria institucional, a partir das perspectivas de perfis específicos: todos docentes, docente com cargo de gestão, docente sem cargo de gestão, todos os técnicos, técnicos com cargos de gestão e técnico sem cargo de gestão. Ainda houve a contribuição para a academia e para o serviço público, pois foi construído um questionário que pode ser reaplicado em qualquer universidade pública.

Dessa forma, o panorama geral do nível de maturidade em GC da UFRPE apontou que existem iniciativas descentralizadas da GC dentro da instituição e o critério Tecnologia alavancou um destaque de boa pontuação. Foi observado que não há uma estrutura formal que lide apenas com esse tema em amplo aspecto com uma liderança ou coordenação centralizada de iniciativas e replicadora de boas práticas em GC. Entretanto, há iniciativas descentralizadas em alguns setores, na percepção dos servidores, e a UFRPE está no nível Iniciação em maturidade 
de GC, o que corresponde ao segundo patamar da escala.

Como sugestão de pesquisas futuras aponta-se a realização de uma pesquisa-ação que visasse implementar um setor de GC na Universidade e assim avaliasse os desdobramentos desse movimento estratégico.

\section{REFERENCIAS}

APO. Productivity in higher education. Research insights for universities and governments in Asia. Tóquio: Asian Productivity Organization, 2017.

APO. Knowledge management tools and techniques manual. Tóquio: Asian Productivity Organization, 20I0.

APO. Knowledge management: facilitator's guide. 2009. Disponível em: $<$ http://www.apotokyo.org/ooe-books/ IS-39_APO-KM-FG.htm> Acesso em: 9 set. 2018.

BATISTA, F. F.; RECH, A. R.; GOMES, C. A.; SANTOS, D. L. N.; ANDRADE, E. C. S.; MALLMANN, M. L.; FERREIRA, R. M. P. M.; COSTA, V. S. Casos reais de implantação do modelo de gestão do conhecimento para a administração pública brasileira. Texto para Discussão IPEA. 2014.

BATISTA, F. F. Modelo de gestão do conhecimento para a administração pública brasileira: como implementar a gestão do conhecimento para produzir resultados em benefício do cidadão. Brasília: IPEA, 2012.

BECERRA-FERNANDEZ, I.; LEIDNER, D. E. Knowledge management: An evolutionary view. ME Sharpe, 2008.

CARVALHO, H. G.; PIMENTA, R. B.; PENTEADO, R. S. Gestão do conhecimento nas organizações. Curitiba: Aymará Educação, 20I2. I2-I4.

CHOUIKHA, M. Organizational design for knowledge management. John Wiley \& Sons, p. 76-I24, 2016.

DAVENPORT, T. H.; PRUSAK, L. Conhecimento empresarial: como as empresas gerenciam seu capital intelectual. Rio de Janeiro: Elsevier, 2003, I4ª reimpressão. I-8

DRUCKER, P., F. O melhor de Peter Drucker: obra completa. São Paulo: Nobel, 2002. I-IO.

EID, M. I. M.; AL-JABRI, I. M. Social networking, knowledge sharing, and student learning: The case of university students. Computers \& Education, v. 99, p. I4-27, 2016.

GONÇALO, C. R; JUNGES, F. M.; BORGES, M. de L. Avaliação da gestão do conhecimento: modelos de mensuração. Anais... Anais do XXX Encontro Nacional de Engenharia de Produção - Maturidade e desafios da Engenharia de Produção: competitividade das empresas, condições 
de trabalho, meio ambiente. 20I0, São Carlos. São Carlos: ENEGEP, 20IO, p. I-I5.

HANDZIC, M. Knowledge management: Through the technology glass. Singapore: World Scientific Publishing, 2004.

NONAKA I., TAKEUCHI, H. Criação de conhecimento na empresa. Rio de Janeiro: Elsevier, I997.

MEYER JR, V. A prática da administração universitária: contribuições para a teoria. Revista Universidade em Debate, v. 2, n. I, p. I2-26, 2014.

MORIN, E.; LE MOIGNE, J. L. A inteligência da complexidade. São Paulo: Editora Petrópolis, 2000.

NOGUEIRA, M. A. Organizações complexas e sociedade da informação: o" sofrimento" como metáfora organizacional. Revista Organizações \& Sociedade, v. IO, n. 28, p. I45-I62, 2003.

SANTIAGO Jr.; SÁTIRO R. J. Gestão do conhecimento. São Paulo: Novatec Editora, p. 2I-25, 2004 .

SANTOS, A. R. (Org). Gestão do conhecimento: uma experiência para o sucesso empresarial. Curitiba: Champagnat, 200I.

SANTOS. S. A.; LEITE. N. P; FERRARESI, A. A. Gestão do Conhecimento: institucionalização e práticas nas empresas e instituições. I. ed. Maringá: Unicorpore, 2007.

SERPRO. Quem Somos. Disponível em: http://www.serpro.gov.br/menu/quem-somos/. Acesso em: II jan. 2019.

SERVA, M.; DIAS, T.; ALPERSTEDT, G. D. Paradigma da complexidade e teoria das organizações: uma reflexão epistemológica. RAE - Revista de Administração de Empresas, v. 50, n. 3, p. $276-287,2010$.

SILVA, S., L. Gestão do conhecimento: uma revisão crítica orientada pela abordagem da criação do conhecimento. Revista Ciência da Informação, Brasília, v. 33, p. I43-I5I, maio/agosto. 2004.

SHAPIRO, C; VARIAN, H. R. A economia da informação: como os princípios econômicos se aplicam a era da internet. Rio de Janeiro: Elsevier, 2003.

STRAUHS, F. R.; PIETROVSKI, E. F.; SANTOS, G. D.; CARVALHO, H. D.; PIMENTA, R. B.; PENTEADO, R. S. Gestão do conhecimento nas organizações. Curitiba : Aymará Educação, 20I2.

SHARIMLLAH DEVI, R.; CHONG, S. C.; LIN, B. Organizational culture and KM practices from the perspective of institutions of higher learning. International Journal of Management in Education, v. I, n. I/2, p. 57-79, 2007. 
SVEIBY, K. E. A nova riqueza das organizações. Rio de Janeiro: Campus, 1998.

TEIXEIRA, F.; GUERRA, O. Redes de aprendizado em sistemas complexos de produção. RAE - Revista de Administração de Empresas, v. 42, n. 4, p. I-I3, 2002.

TRAGTENBERG, M. A escola como organização complexa. Revista Educação \& Sociedade, V. 39, n. I42, 2018.

TODERICIU, Ramona; ŞERBAN, Anca. Intellectual Capital and its relationship with universities. Procedia Economics and Finance, v. 27, p. 713-7I7, 2015.

TURBAN, E. RAINER, K.; POTTER, R. Administração de tecnologia da informação: teoria e prática. Rio de Janeiro: Elsevier, 2005. 